\title{
IDEALISED, SEXY AND DISSOLUTE - THE PORTRAYAL OF CONTEMPORARY WOMEN IN THE CONTEXT OF AMERICAN PORNOGRAPHIC MAGAZINES (ON THE EXAMPLE OF "PENTHOUSE"')
}

\begin{abstract}
This paper provides an account of the representation of women in contemporary American pornographic magazines and investigates the role that stereotypes and idealized cognitive models play in determining how a woman - as a word and a concept - functions in the contemporary pornographic press. It is predominantly based on the assumption that the ICM of a woman is a metonymic model comprising several submodels. As a matter of fact, the ICM presented in the analysed material, actually does not have a complicated structure. We can assume that the "Penthouse" magazine clearly popularizes one kind of woman based mostly on the submodels such as LOVE ${ }^{3}$ AND SEX, BODY, PHYSICAL TRAITS and PSYCHOLOGICAL FEATURES AND PROCESSES ${ }^{4}$ which take dominance over the others and lead to discriminatory assumptions and generalizations.
\end{abstract}

Keywords: man, woman, pornography, magazine, ICM.

\section{INTRODUCTION}

There is a vast number of things and phenomena in today's world that we can classify as significant, but substantially sex belongs to the very essentials. The intensity of the sex drive has a much bigger influence than most people are even aware of. There are some individuals for whom it is not an indispensable aspect of existence; some others think about sex-related occurrences practically all the time. When we take into consideration some magazines for men, it is easy to notice that a woman constitutes the core of their interests. The

\footnotetext{
${ }^{1}$ Karolina Kurowska, MA, the Institute of English Studies, University of Rzeszów, Al. mjr. W. Kopisto 2 B, 35-315 Rzeszów; e-mail: karolinakurowska@onet.pl. ORCID: 0000-0002-4529$-444 X$.

2 "Penthouse" is a men's magazine founded by Bob Guccione, ranked among the group of pornographic magazines. It contains articles associated with urban lifestyle and various pornographic pictorials.

${ }^{3}$ It must be noted that the results presented in this study finally divide this particular submodel, as pornography relates only to sex.

4 This article adopts the following typographic conventions: 1) bold capitals are used for the names of ICMs; 2) bold small capitals are used for the names of submodels; 3 ) capitals are used for abstract concepts; 4) italics are employed for the names of key terms; 5) bold italics are used for lexemes and names of lexical units; 6) single quotation marks are employed for explanations and definitions; 7) angles are used to present metonymic patterns.
} 
image of women in the consciousness of a contemporary man and their role and position in Western culture is shaped not only by individual experience, but also by centuries-old collective experience, perpetuated by customs, religion, law and art. Nowadays, however, views about women are constantly influenced by the press, and are attributed with certain features along with their positive or negative valorisation ${ }^{5}$. As Gunter (2002) observes: "Media $\operatorname{sex}^{6}$ has been accused of undermining social mores, promoting sexual promiscuity, the early onset of sexual behaviour and teenage pregnancy rates, and producing distorted male (and female) beliefs about female sexuality." A wide range of possibly detrimental, psychological and social consequences of constant exposure to media sex have been emphasised, hence the article considers the spread and prominence of stereotypes in pornographic magazines and their allegedly harmful effects that follow, since "although media sex is publicly criticised, it is also publicly consumed" (Gunter, 2002).

For the purpose of the analysis, 21 issues of the magazine "Penthouse" published from January 2016 to December 2017 were collected and thoroughly examined. The research procedure is simplified, and the focus is on tracking the encyclopedic knowledge ${ }^{7}$ in the lexical layer. The collected linguistic material was limited to the lexeme woman (in singular or plural forms) omitting all its synonyms like girl, female or chick which can also be detected in this kind of magazines. Importantly, it is believed here that the precise notion of an Idealised Cognitive Model, as proposed by Lakoff (1987), provides the best framework for a comprehensive description of the concept of WOMAN, as this proposal, despite its appealing character, contains a purported empirical basis and it cannot be easily rejected. Yet, it is of paramount importance to recognise the fact that although ICMs are in principle individual, they are shared within a given culture ${ }^{8}$ and perpetuated by the contemporary media. In view of this, the aim of this small-scale study is to identify and analyse the potential submodels that appear in modern pornographic magazines and which contribute to the supposedly stereotypical and negative structure of the WOMAN ICM in Western culture.

\section{PORNOGRAPHIC MAGAZINES}

The word pornography ${ }^{9}$ generally refers to sexually explicit images and words whose exclusive purpose is sexual arousal. Although criticised by various social circles, the development of technology in the last several years has upgraded pornography to a powerful and extremely pervasive form of art. It is no longer associated with dirty magazines, but rather with glossy and glamorous publications ${ }^{10}$ filling store shelves. The apparent mechanism of

5 Sometimes implicitly, but very often consciously and deliberately.

${ }^{6}$ Gunter (2002) conducts the research on the depiction of sex in the mainstream mass media, such as film, television, video and magazines (also pornographic magazines), trying to discover the alleged effects that such content might have upon consumers.

${ }^{7}$ Encyclopedic knowledge is seen here as structured and arising in the specific context of its usage (see Langacker, 2008).

8 On this issue consult Gibbs (1999) and Kövecses (2005).

${ }^{9}$ It is worth noting at the very beginning that the term pornography no longer conjures up images of a beautiful housewife engaged in a romantic relationship with a lonely neighbour. The Internet has significantly changed the content and perception of porn. Now, a great deal of the most easily accessible and popular forms of pornography contain meaningful amounts of humiliation, violence, and degradation of women. They are short, dynamic and predominantly focused on genitalia.

${ }^{10}$ One interesting thing about popular culture is that men's magazines and women's magazines often follow the same general formula. Men's magazines are mostly based on heavily eroticized images 
reception of such kind of magazines assumes that the male reader acknowledges the linguistic image of women encountered in the magazine and starts to create their own picture in order to avoid the inconsistency between reality and what is presented in the contemporary pornographic press. In this way, the role of the media, which in the era of the information society still have an important share in shaping all social norms and values, is emphasised. They create and model reality as intended by the publisher. What is more, "The combination of 'babes' and booze is an unbeatable moneymaker" (Cheney, 2004), which makes the pornographic market continuously lucrative.

It should be emphasised, however, that for many, pornography is not an artistic act or erotic message, but rather is completely devoid of aesthetic and cognitive value. Its essence depends on the main function, which is sexual stimulation. Pornography is widely criticized, in particular, by feminist circles. Their conception of pornography is very broad ${ }^{11}$, yet very often it concerns some sexual situations in which the image of a woman is based on subordination and instrumentalisation. Środa (2009) points out that it builds and strengthens the stereotype of a woman as a servant towards men; it gives permission to oppress women and to promote violence against them. The whole issue is not merely a linguistic quibble, on the contrary, it constitutes the crux of women's existence in the patriarchal world. Kappeler (1994) further notices: "Women in our culture have been seen primarily as bodies - sexual bodies designed for sex and reproduction (though very useful in productive labour too)". For this reason, male magazines, especially erotic ones, can pejoratively shape the image of a contemporary woman.

\section{SOME THEORETICAL PREREQUISITES}

Human categorization constitutes one of the major, and most significant issues in Cognitive Linguistics, simply because the ability to categorize different phenomena is an essential part of cognition. Categorization might be seen as an unconscious, automatic process, yet the whole issue seems to be more complicated. How people judge and establish different categories has been discussed since time immemorial and it dates as far back as to Aristo$\mathrm{tle}^{12}$, whose views on categorisation survived unchanged for many years, until they became disproven by Rosch (cf. 1973, 1977, 1978), who proposed a model of categorisation based on the concept of prototype ${ }^{13}$. Another meaningful reconsideration of the prototype view emerges in 1987 in George Lakoff's book Women, Fire, and Dangerous Things. Especially the theory of idealised cognitive models ${ }^{14}$ (Lakoff, 1987), appears to be one of the most valuable applications of the findings concerning prototype effects in categorisation.

of women. Interestingly, women's magazines are sometimes centred around heavily eroticized images of women as well.

${ }^{11}$ It might refer to many different aspects, from 'soft core' celebrity pics, where a famous person chooses to have some nude pictures, all the way to hard core videos of violent and illegal acts.

12 The Aristotelian view holds that categories can be defined in terms of a conjunction of the necessary and sufficient features that every member of a particular category has to exhibit. Such requirements not only imply that categories have clear and impregnable boundaries, but also that all the members belonging to a particular category have equal status (Taylor, 1995).

13 The prototype theory assumes that every category has two types of members: the prototype and several other members, which are less central, and which are related to the prototype (the most typical and the most prominent member of a category) in a motivated way.

14 Henceforth ICM. 
As stated above, Lakoff's view of categorization ${ }^{15}$ is focused on Idealised Cognitive Models which can be understood as conventionalised patterns of belief used in the process of understanding (Lakoff, 1987). His proposal concerning ICMs is strongly grounded in the empirical findings of cognitive psychology on prototype effects (Rosch, 1978). Obviously, the outside world is full of various (often conflicting) signals of which humans are trying to make sense; stereotypes help us perform this task. In many cases, when one has to deal with such complicated concepts as WOMAN, one simple ICM is not enough to define their meaning. Therefore, Lakoff coined the structure known as the cluster model, which involves combining several cognitive models into one complex cluster that is "psychologically more basic than the models taken individually" (Lakoff, 1987). As a result, the semantic categories of the concepts of WOMAN should be described not as one single ICM, but rather as a cluster consisting of many different aspects that best define the category in question. For example, a woman is not only a person who cares about clothes and external appearance, or one who stays at home as a housewife, taking care of children and her husband. The understanding of the concept of WOMAN requires reference to a cluster of several ICMs such as family model ('a person who is the main caregiver'), sex model ('the female who enjoys her sex life'), or physical traits model ('a person who cares about looks, weight and diet'). Therefore, it must be emphasised that stereotypes (and ICMs in general) are holistic cognitive structures which make our lives easier by lending some coherence and order (Hogg, Vaughan, 2002). To put it differently, stereotypes offer an economy of thinking by reducing the cognitive effort necessary to interpret reality.

Summarizing, the ICMs not only contribute to our comprehension of a given culture, but they also reflect the social values and beliefs that define cultural groups. For this reason, an idealized cognitive model constitutes a cognitive structure which is idealized so as to represent reality from a particular perspective. ICMs offer a mental representation of an area of experience that does not usually match reality and in this way, they are able to shape the way human beings perceive the world. Kövecses (2005) notices that the meaning of a word is culture-dependent, inherently subjective, and depends solely on the kind of mental representation people use to comprehend it. Similarly, the image of gender is motivated by objective properties of objects as well as by subjective factors, e.g. the point of view of a given magazine. A set of such factors seems to create a stereotype that contains not only descriptive but also axiological contents, such as values norms or personal patterns. The WOMAN ICM presented and analysed below can be perceived as a conceptual network (cluster) that consists of one general definer: a woman, and several related prototypical associations (the network built by submodels). Once the network of the concept WOMAN is activated, we obtain a whole set of propositions that are neatly arranged according to their degree of centrality. In this way, the source of prototype effects is created. In order to obtain a full picture of this phenomenon, the examples excerpted from the magazines were divided into ten submodels ${ }^{16}$, corresponding to the content of the magazine, and several dozen aspects that allow a more precise systematization of the material.

${ }^{15}$ For a better elucidation of the categorization process from the cognitive perspective see e.g. Evans and Green (2006).

16 When determining the names of submodels and aspects constituting their further and more detailed developments, I mainly used the work of Spychała-Reiss (2009), though with some changes and new details selected for the purpose of the analysis. 


\section{THE ANALYSIS}

The further part of this article contains an outline of the most common aspects identified in the analysis which can be assigned to various submodels belonging to and creating the whole cognitive model of WOMAN, such as BODY, FASHION AND CLOTHES, PHYSICAL TRAITS, PHYSICAL PROCESSES AND ACTIVITIES, PSYCHOLOGICAL FEATURES AND PROCESSES, WORK AND EDUCATION, LEISURE, SOCIAL LIFE, LOVE AND SEX, and FAMILY LIFE. As one might expect, the list of submodels discussed below cannot be seen as closed and complete. However, it is strongly believed here that this account exhaustively covers the areas describing modern women, at least within Western civilisation. One of the negative aspects of the theory of ICMs is that in media discourse there is a predominant tendency towards strong idealisation and stereotyping of women in popular magazines (also those with pornographic content). This demonstrates the cognitive structuring of reality in the human mind - the submodels such as LOVE AND SEX and PHYSICAL TRAITS form the idealised prototype of the category in question ${ }^{17}$. The positive aspect, on the other hand, allows the existence of many submodels which reflect the views of society precisely and from a much wider perspective.

\subsection{Submodels and their Internal Division}

Obviously, some of the submodels are more productive than others. Although the percentage distribution may be helpful, a simple table presenting the quantitative data in detail should be both supportive and accommodating in comprehending the material.

Table 1. The number of excerpts found in "Penthouse" divided into submodels of the WOMAN ICM

\begin{tabular}{|c|l|c|}
\hline No. & \multicolumn{1}{|c|}{ Submodels of WOMAN ICM } & Excerpts \\
\hline 1. & BODY & 17 \\
\hline 2. & FASHION AND CLOTHES & 23 \\
\hline 3. & PHYSICAL TRAITS & 66 \\
\hline 4. & PHYSICAL PROCESSES AND ACTIVITIES & 25 \\
\hline 5. & PSYCHOLOGICAL FEATURES AND PROCESSES & 109 \\
\hline 6. & WORK AND EDUCATION & 20 \\
\hline 7. & LEISURE & 20 \\
\hline 8. & SOCIAL LIFE & 19 \\
\hline 9. & LOVE AND SEX & 122 \\
\hline 10. & FAMILY LIFE & 45 \\
\hline TOTAL & & 466 \\
\hline
\end{tabular}

A detailed description of the collected language material is presented below. Excerpts containing the lexeme woman have not only been assigned to specific submodels, but they have been further divided into more detailed subcategories that helped in the process of categorization $^{18}$.

17 The most represented submodels of the complex cluster usually characterise the most typical representative of a category, that is the prototype.

${ }^{18}$ It should be underlined that some of the examples, due to the fact that they concern different thematic areas, have been assigned to more than one thematic category, simply because it is not always 
Table 2. The number of excerpts found in "Penthouse", divided into submodels of the WOMAN ICM and their internal division

\begin{tabular}{|c|c|c|c|c|}
\hline No. & $\begin{array}{l}\text { Submodels of } \\
\text { WOMAN ICM }\end{array}$ & $\begin{array}{l}\text { Number } \\
\text { of excerpts }\end{array}$ & Aspect covered by particular submodels & $\begin{array}{l}\text { Number } \\
\text { of excerpts }\end{array}$ \\
\hline 1. & BODY & 17 & $\begin{array}{l}\text { a) hair } \\
\text { b) face, skin, body } \\
\text { c) breasts }\end{array}$ & $\begin{array}{c}2 \\
15 \\
10 \\
\end{array}$ \\
\hline 2. & $\begin{array}{l}\text { FASHION } \\
\text { AND CLOTHES }\end{array}$ & 23 & $\begin{array}{l}\text { a) clothes and shoes } \\
\text { b) elegance, good look }\end{array}$ & $\begin{array}{l}11 \\
12\end{array}$ \\
\hline 3. & PHYSICAL TRAITS & 66 & $\begin{array}{l}\text { a) attractiveness, beauty } \\
\text { b) bodybuilding, weight, diet } \\
\text { c) age } \\
\text { d) cosmetics and hygiene }\end{array}$ & $\begin{array}{c}50 \\
1 \\
12 \\
3 \\
\end{array}$ \\
\hline 4. & $\begin{array}{l}\text { PHYSICAL } \\
\text { PROCESSES } \\
\text { AND ACTIVITIES }\end{array}$ & 25 & $\begin{array}{l}\text { a) food, cooking } \\
\text { b) sleeping } \\
\text { c) crying } \\
\text { d) death } \\
\text { e) health, illnesses } \\
\text { f) pregnancy, fertility, abortion } \\
\text { g) pain, physical suffering }\end{array}$ & $\begin{array}{c}1 \\
0 \\
0 \\
1 \\
8 \\
13 \\
2 \\
\end{array}$ \\
\hline 5. & $\begin{array}{l}\text { PSYCHOLOGICAL } \\
\text { FEATURES } \\
\text { AND PROCESSES }\end{array}$ & 109 & $\begin{array}{l}\text { a) fear, confusion, stress } \\
\text { b) loneliness } \\
\text { c) sadness, bad mood, depression } \\
\text { d) shame } \\
\text { e) joy, enthusiasm, happiness } \\
\text { f) thinking, overthinking, wondering } \\
\text { g) dreams, desires } \\
\text { h) self-analysis, criticism } \\
\text { i) intelligence } \\
\text { j) life experience } \\
\text { k) mental fatigue } \\
\text { l) activity, resourcefulness, strength } \\
\text { m) passivity, helplessness, apathy, feel- } \\
\text { ing of discrimination } \\
\text { n) feeling of freedom, independence, } \\
\text { emancipation } \\
\text { o) guilt } \\
\text { p) responsibility } \\
\text { q) self-esteem, confidence, sense of secu- } \\
\text { rity } \\
\text { r) mental health, feeling of abuse } \\
\text { s) support, advice, sharing } \\
\text { t) violence, aggression }\end{array}$ & $\begin{array}{c}3 \\
0 \\
1 \\
0 \\
0 \\
3 \\
3 \\
4 \\
2 \\
2 \\
0 \\
18 \\
28 \\
\\
12 \\
\\
1 \\
0 \\
7 \\
\\
4 \\
10 \\
11\end{array}$ \\
\hline
\end{tabular}

easy to identify the submodel emerging from a specific phrase. For this reason, apart from clear cases that involve the activation of one particular submodel, there are some elements of the encyclopedic knowledge of the lexeme woman that require the activation of more than one submodel. 
Table 2 (cont.). The number of excerpts found in "Penthouse", divided into submodels of the WOMAN ICM and their internal division

\begin{tabular}{|c|c|c|c|c|}
\hline No. & $\begin{array}{l}\text { Submodels of } \\
\text { WOMAN ICM }\end{array}$ & $\begin{array}{l}\text { Number } \\
\text { of excerpts }\end{array}$ & Aspect covered by particular submodels & $\begin{array}{l}\text { Number } \\
\text { of excerpts }\end{array}$ \\
\hline 6. & $\begin{array}{l}\text { WORK } \\
\text { AND EDUCATION }\end{array}$ & 20 & $\begin{array}{l}\text { a) promotion, career } \\
\text { b) work, profession, work environment } \\
\text { c) education } \\
\text { d) earnings, economic situation, position }\end{array}$ & $\begin{array}{l}8 \\
5 \\
3 \\
4\end{array}$ \\
\hline 7. & LEISURE & 20 & $\begin{array}{l}\text { a) holidays } \\
\text { b) alcohol, drugs } \\
\text { c) parties, social meetings } \\
\text { d) sport, games }\end{array}$ & $\begin{array}{c}0 \\
13 \\
0 \\
7\end{array}$ \\
\hline 8. & SOCIAL LIFE & 19 & $\begin{array}{l}\text { a) shopping } \\
\text { b) community, social and political activity }\end{array}$ & $\begin{array}{c}1 \\
18\end{array}$ \\
\hline 9. & LOVE AND SEX & 122 & $\begin{array}{l}\text { a) sexual techniques and behaviours } \\
\text { b) betrayal, divorce } \\
\text { c) contraceptives } \\
\text { d) prostitution } \\
\text { e) pornography }\end{array}$ & $\begin{array}{c}94 \\
2 \\
3 \\
8 \\
15\end{array}$ \\
\hline 10. & FAMILY LIFE & 45 & $\begin{array}{l}\text { a) marriage, relations, love } \\
\text { b) children, upbringing } \\
\text { c) family } \\
\text { d) housekeeping }\end{array}$ & $\begin{array}{c}40 \\
4 \\
1 \\
0\end{array}$ \\
\hline
\end{tabular}

\subsection{Metonymic Model}

Metonymy is defined as "a cognitive process in which one conceptual entity, the vehicle, provides mental access to another conceptual entity, the target, within the same domain, or ICM" (Kövecses, Radden, 1998: 39). This view suggests that humans acquire access to a mental activity via another mental activity. According to the methodological assumptions undertaken here, the stereotypes of WOMAN can be best described as a metonymic ICM in which the prototypical member of a given category stands for the whole category (hence <PART FOR WHOLE>) or a particular characteristic feature describes and stands for the whole category, in compliance with cultural expectations (Lakoff, 1987). The activation of a particular submodel provides access to the whole ICM. In other words, it can be stated that such a submodel serves as a vehicle through which the target (that is, the WOMAN ICM) can be accessed. For this reason, metonymy may constitute a typical cognitive mechanism involved in the formation of a stereotypical model of a woman. Indeed, it seems logical to assume that the target concept is that of WOMAN. The vehicle, on the other hand, can be best characterised as a particular ATTRIBUTE or a PERSON possessing those attributes, which inevitably suggests the frequent metonymic patterns presented in the analysis:

- $<$ ATTRIBUTE FOR WOMAN>,

- <ATTRIBUTE POSSESSOR FOR WOMAN>. 


\subsubsection{The structure of the WOMAN ICM}

As suggested earlier, for more complex notions, one should expect to find a cluster of models, hence it can be best described as the WOMAN ICM which consists of a cluster of metonymic models. The phenomena and experiences involved in this cluster can be graphically presented as follows:

\section{WOMAN ICM}

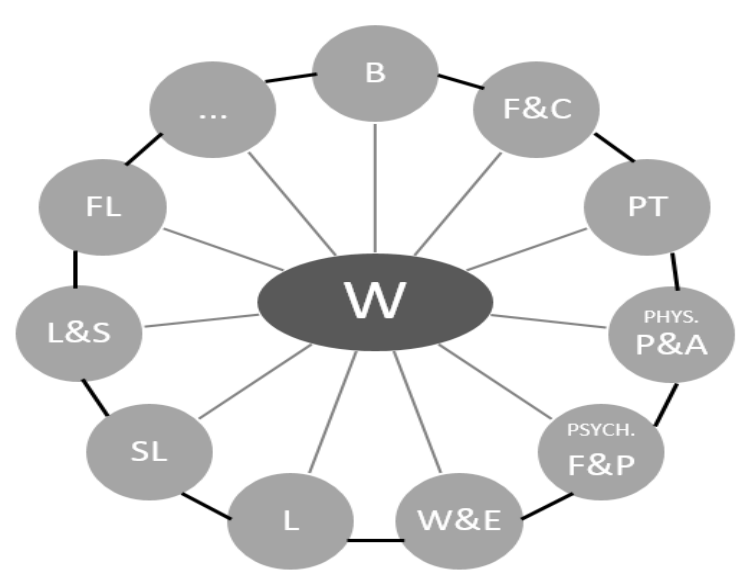

WOMAN ICM

W - Woman

SUBMODELS of WOMAN

ICM

B - Body

F\&C - Fashion and clothes

PT - Physical traits

PHYS. P\&A - Physical

processes and activities

PSYCH. F\&P - Psychological

features and processes

$\mathbf{W} \& \mathbf{E}$ - Work and education

L - Leisure

SL - Social Life

L\&S - Love and sex

FL - Family life

... - other submodels

Fig. 1. A simplified graphic representation of the WOMAN ICM in "Penthouse"

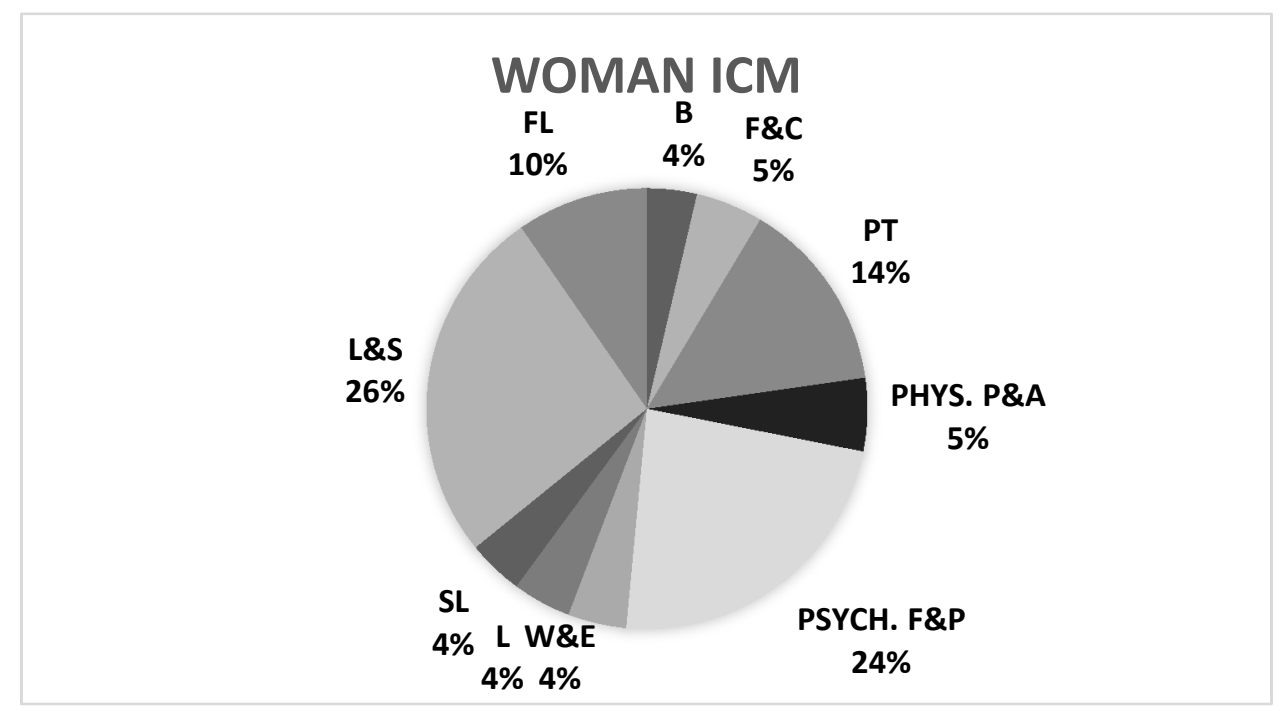

Fig. 2. Productivity of submodels of the WOMAN ICM 
The larger inner element represents the concept WOMAN; hence it constitutes the core, from which a number of extended submodels, represented by smaller outer circles emerge. The smaller outer circles (that is, the submodels) are obviously connected to the central point, but also to one another. Thus, the information that a woman cares about her appearance may activate other beliefs about her as a member of this group, concerning for instance education or sex life. Using more technical terminology, the submodel BODY that belongs to the WOMAN ICM provides a point of access to the whole network (cf. Langacker, 1987).

Proceeding further, let us now look at the different poles of femininity and consider how much the image of a woman presented in the pornographic press is subjected to unfair simplifications and stereotypes and what possible implications such depictions may have.

\subsection{In-depth Analysis}

The lexeme woman appears in the analysed issues of the "Penthouse" magazine up to 466 times. It seems that the WOMAN ICM is strongly dominated by features such as BODY, PHYSICAL TRAITS, PSYCHOLOGICAL FEATURES AND PROCESSES and LOVE AND SEX. These four submodels demonstrate the way in which pornographic media depict female gender ${ }^{19}$. Firstly, women are merely sexualised objects recognised by their sexy and alluring appearance, which falsely implies that men, recognised by other characteristics, are the cultural standard and women are unimportant or they serve specific purposes. Secondly, pornographic magazines create the impression that most women lead a lush erotic life and sexual desire is one of the most important exponents of femininity. Thirdly, depictions of the relationships between men and women emphasise their fleeting and affair-oriented attitude; they can also normalise violence against women. Each of these themes will be considered separately in the following sections.

\subsubsection{LOVE AND SEX Submodel}

As is apparent from the above tables, women are clearly defined in "Penthouse" in terms of the LOVE AND SEX submodel - the lexeme appears in this connection 122 times, whereas as many as 94 examples refer to the sexual techniques and behaviours category. For this reason, women seem to be primarily perceived in terms of their sexual encounters. They are presented as sexually active and open to new experiences. In addition, such entertainment format depicts females as easy sexual conquests whose principal role is to gratify male sexual needs. Such portrayals, it is argued, can send the wrong messages about women and their sexuality. The claims like:

"We worked up a good rhythm quickly and she started to buck me like a wild woman... rocking the headboard...thump thump thump thump thump thump." "Penthouse" 9/2017.

"Normally, I would consider watching a beautiful woman masturbate to be an amazing moment, however, I was more bewildered." "Penthouse" 7-8/2016.

${ }^{19}$ What has to be stressed at this point is the fact that the particular traits and dimensions identified in the study should not be seen as limited to the submodel to which they have been assigned, but rather they should be interpreted as providing access to the whole network. They would obviously also show different distribution in different kinds of magazines. In this case, however, they mostly carry a negative axiological load and gender-related stereotypes. 
describe women as obsessed with sex, and willing to engage in any kind of sexual act with any partner. It further creates the impression that they are easy-going and easily accessible for sex. What is more, they make use of various sexual toys, which makes their erotic lifestyle even more adventurous:

"Sexciter makes women hot and desire sex." "Penthouse" 2/2016.

“After these developments, it didn't take long for the vibrator to find its way into women's rooms all over America. Women, it seemed, could not get enough of this revolutionary new 'treatment'." "Penthouse" 4/2016.

The image of an always sexually willing woman causes some concerns and might contribute to mistaken perception among men of female sexuality and their allegedly daring attitudes in their intimate contacts:

"A blowjob a day is one way I take care of him. In fact, that's something every woman should be doing for her man." "Penthouse" 4/2017.

In this way, it might lead to unwanted, unusual, and sometimes even abnormal sexual activities $^{20}$. Pornography can sometimes dominate heterosexual men's sexual encounters with women. Frequent exposure to pornographic content may be associated with greater reliance on and preference for the pornographic script during interpersonal intimate encounters. Many men appreciate women who have knowledge and experience in the erotic sphere, which is confirmed by the following example:

"Praise to the women who taught us to be good in bed." "Penthouse" 11/2017.

In other words, pornography is not merely a fantasy for men; it frequently shapes how they engage in intimate behaviours. Furthermore, magazines such as "Penthouse" cultivate a particular set of beliefs about the relative dominance and power of men over women in society:

"This is the stigma around sex, and it's a problem. Why can't a woman be sexually active, talk about her sex life, and at the same time be with the mayor doing (community) things?" "Penthouse" 11/2017.

While the present research is yet not able to provide a strong proof of this phenomenon, it could be suggested that pornography is strongly correlated with factors widely recognized as gender inequality and hostile attitudes towards women. It actually feeds a culture that views women as sexual objects, unprepared to occupy high political positions, whose lush erotic lifestyle can lead to social exclusion and degradation. Women are best described in reference to the submodel LOVE AND SEX (by far the most productive model) and the metonymic associations like <SEXUALLY ACTIVE PERSON FOR WOMAN>,

${ }^{20}$ It is often claimed that such content can contribute to difficulties in saying no in real life what might inevitably lead to rapes, as pornography fuels some criminal behaviour and practises (see e.g. Gunter, 2002). 
<VOLUPTUOUS PERSON FOR WOMAN>, <ALLURING PERSON FOR WOMAN> frequently appear.

\subsubsection{PSYCHOLOGICAL FEATURES AND PROCESSES Submodel}

The PSYCHOLOGICAL FEATURES AND PROCESSES submodel is also very productive when it comes to women, as it emerges from as many as 109 excerpts (24\% of the material collected). While it cannot be predicted with complete certainty that such a model is also productive in all types of magazines for men, it points to the fact that the men who read "Penthouse" are interested in the feminine psyche, their principles of functioning and thinking. The occurrence may be illustrated by the following descriptions and statements.

The media have presented two images of women: good women and bad ones. These polar opposites are often juxtaposed against each other to dramatize differences in the consequences that befall good and bad women. Bad women are attractive, focused on a professional career and successful in their social and erotic lives. This type definitely dominates pornographic magazines and is unquestionably preferred by their readership. Most females are therefore represented as hard, cold, aggressive; hence, all of the things that a good woman is not supposed to be, which inevitably creates another powerful metonymic stereotype <BITCH FOR WOMAN>:

"Every woman has a high-maintenance bitch inside her." "Penthouse" 11/2017.

"I really like strong women." "Penthouse" 1/2016.

What is more, some articles in "Penthouse" surprisingly encourage them to take the initiative and free themselves from traditional roles and limitations:

"We hope that this pictorial serves as an inspiration to all women to raise their middle finger to any and all who would try to hold them back." "Penthouse" 4/2017.

"Why do you think so many men are still afraid of strong, powerful women?" "Penthouse" 4/2017.

"Gone are the days of the Titanic, when men stayed behind while the women and children were rescued. Soon, women may have to forcibly take up arms alongside their male counterparts and, like them, go down with the ship. "Penthouse" 10/2016.

Looking from the opposite perspective, good women are pretty, deferential and caring for others. They are frequently subordinate to men, usually cast as victims, angels and loyal wives and helpmates. They also exemplify traditional stereotypes of femininity such as passivity, subservience; they are not too able, too powerful, or too confident. They look up to the man and depend on him, waiting for the proverbial rescue:

"I love the feeling of rescuing a woman from a bad situation." "Penthouse" 11/2016.

Subjection is also a typical feature assigned to a woman and it is strongly rooted in people's consciousness, which can easily be demonstrated by the rich material. It may result from the working of the <INSECURE PERSON FOR WOMAN> metonymy. In the sexual 
sphere, women are usually presented as passive, objectified sexual objects, aimed at satisfying masculine needs, while men are assigned the role of often polygamous conquerors and undisputed rulers of women ${ }^{21}$ :

"Men do not communicate about women - a man's sexual conquest of a woman like this." "Penthouse" 1-2/2017.

"Sure, of course, men objectify women, usually when men gather at a man-event." "Penthouse" 1-2/2017.

In this way, attractive women are perceived as sexual conquests to be won and flaunted in front of other men. To a large extent, such sentences reflect the patriarchal order of the world in which women constitute a second, vulnerable, worse sex with a whole range of flaws and vices. What is more, the feminine logic is definitely seen as negative and dismissive.

"They are just offering them to women who aren't good at parking." "Penthouse" $7 / 8 / 2016$.

Another interesting application of this idea is that women are difficult to understand. The stereotype emerges in the following example:

"Women are complicated." "Penthouse" 11/2017.

One has to bear in mind, however, that aspects such as lust, licentiousness, passivity, helplessness, aggression and many more, are not the only labels with assigned semantic encyclopedic knowledge that appear in relation to women. The categorization of females made in the magazine under study reveals a much larger number of associations, which will be analysed in the following part.

\subsubsection{BODY and PHYSICAL TRAITS Submodels}

Pornographic magazines are often seen as a means of sexual expression, especially because female bodies have historically been rigidly controlled by restrictive sexual norms and practices. The contemporary media offer an accessible way to seemingly resist and challenge such restrictions. However, as the pornography market is dominated by an industry with economic interests in the control of women's bodies, it seems that its main role is simple disposal of other women's bodies for male pleasure and profit.

Because pornography can be treated as a specific medium that spotlights the body and often utilizes women that conform to cultural appearance ideals, the magazines such as "Penthouse" can be considered a potential source of appearance-related pressure. They continuously disseminate images of bodies adhering to inflexible and unrealistic appearance standards, and individuals cannot escape these images due to their omnipresence ${ }^{22}$ :

${ }^{21}$ That seems to confirm the existence of the metonymic associations: 〈CONQUEROR FOR MAN〉, $<$ CONQUERED FOR WOMAN>.

22 Media images of perfect bodies not only inform women how they are supposed to look but also what kind of girlfriends and wives they are supposed to be (see Gunter, 2002). 
"Who doesn't like nude, beautiful women?" "Penthouse" 2/2016.

"As with every issue, though, everything revolves around the photographs of beautiful women." "Penthouse" 2/2016.

"They are very natural and I think it makes a woman more beautiful and sexy."

"Penthouse" 1-2/2016.

"I turned around to see a gorgeous, raven-haired woman beaming at me." "Penthouse" 9/2017.

Clearly, the representation of the female body in pornography creates a normative ideal of how a woman should look to be attractive. These superficial attributes are very often impossible to reach naturally. Moreover, in addition to an immaculate appearance, a modern woman is to be attractive and sexy (50 excerpts):

"Yeah, yeah, so she's been named 'Sexiest Woman Alive' by Esquire - twice."

"Penthouse" 1-2/2017.

"On the first day of my tutorial, I walked into the classroom and saw the hottest woman I had ever seen." "Penthouse" 5/2017.

The pornography industry does not emancipate women from restrictive sexual practices; instead it repackages sexual control as a commercial product and markets it to women as a form of sexual choice. Thus pornographic magazines present dissonant messages - pornography is marketed as sexual empowerment, but the content is violent and dehumanizing, particularly to the women who are in the industry, which is also confirmed by the phrase:

"Many moons ago, I was in Rio de Janeiro, where the local economy depends almost entirely on the exploitation of its most abundant natural resource: young, gorgeous women." "Penthouse" 9/2017.

The featuring of women merely as 'sex objects' in male magazines is suported by the examples below, which consider the women's body as the main object of interest, and feature female body parts more than the entire individual and more than their faces ${ }^{23}$. A woman is often symbolised as Barbie, and represented with a thin body, blond hair and large breasts:

"Standing before me was a blonde, blue-eyed young woman with a Barbie doll figure that defied belief." "Penthouse" 1/2016.

"She was by far the most attractive woman that I had ever been with - amazing body, flawless tits, and save for a cute little lacy thong, she was naked ... in my bed." "Penthouse" 1-2/2017.

${ }^{23}$ The lexeme woman appears in this submodel 17 times, and mostly in connection to breasts and bottom. 
"You have the physical beauty, obviously. I like a woman with nice thighs, a nice ass, and that has poise. It's fun when I can banter with a woman and talk shit." "Penthouse" 10/2017.

"She is my idea of what a beautiful, sexy woman should look like: long blonde hair and huge jugs." "Penthouse" 11/2017.

Such a multitude of examples testifies to the objectification of the female body. Very often men's magazines refer to particular parts of a woman's body in an extremely negative and degrading manner, which is evident from the statements below:

"We love it when a woman's brain is as big and juicy as her ass." "Penthouse" $12 / 2017$.

"I prefer a woman with a big backyard." "Penthouse" 4/2016.

"He looks at a woman as one may look at a bunch of Lego pieces. A pile of 'its.' Things. Bits and pieces." "Penthouse" 4/2016.

To summarise, the BODY and PHYSICAL TRAITS submodels seem to be productive and occupy an essential position in reference to women. A conclusion that emerges from the aforementioned findings is that a woman appears to be perceived above all in terms of her sexuality and physical appearance (17 examples fall within the scope of the BODY submodel hence hair, face, skin, breasts and body in general; whereas 66 excerpts lie within the scope of the PHYSICAL TRAITS submodel, therefore including features associated with attractiveness, beauty and $\mathrm{age}^{24}$ ). Having surveyed this issue from various angles, it can be suggested that the strongest gender stereotypes for women to be found in "Penthouse" magazine are those that allow them to be perceived as sexualised objects subjected to men and created for their pleasure. But although this collection cannot give the full flavour of the contemporary image of every woman on the planet, it depicts one frame of reference according to which millions on women are judged and evaluated by some men.

\section{CONCLUDING REMARKS}

Of the many influences on how we view men and women, the print media are one of the most pervasive and one of the most powerful ones. Woven throughout our daily lives, they possess the power to insinuate their messages into our consciousness. Furthermore, many images of the sexes presented and popularised by the contemporary pornographic media perpetuate unrealistic, stereotypical, and limiting perceptions.

Firstly, a woman depicted in "Penthouse" magazine possesses an attractive body (17 excerpts - BODY submodel) and is interested in clothes and fashion (23 excerpts - FASHION AND CLOTHES submodel). She is beautiful, young (66 excerpts - PHYSICAL TRAITS submodel), and leads a lively social life, goes on dates and parties and has a wide circle of

\footnotetext{
${ }^{24}$ Hence the attributive functions of SEXPOT and BARBIE stand metonymically for the whole category of WOMAN (<SEXPOT FOR WOMAN $>$, <BARBIE FOR WOMAN $>$ ).
} 
friends. In addition, she tries to be active, resourceful and fight for independence (PSYCHOLOGICAL FEATURES AND PROCESSES submodel - activity, resourcefulness, strength, 18 excerpts; feeling of freedom, independence, emancipation, 12 excerpts), but sometimes she struggles with various problems related to her psychological wellbeing. She frequently reflects on herself (PSYCHOLOGICAL FEATURES AND PROCESSES submodel - passivity, helplessness, apathy, feeling of discrimination, 28 excerpts) and experiences physical and psychological violence and abuse (PSYCHOLOGICAL FEATURES AND PROCESSES submodel - violence, aggression, 11 excerpts).

Secondly, the common narrative of femininity in the pornographic magazines under scrutiny is the one that a woman can be successful but at the same time sexy and alluring. She is usually young, slim, provocatively dressed and willing to engage in sexual interaction with men. A different kind of woman is either not depicted at all, or diminished, ridiculed and featured as a victim. As Wykes and Gunter imply (2005: 96): "Women are not newsworthy unless sexualized". Magazines such as "Penthouse" provide female bodies for men. They convey the message that female bodies are objects to be used for their enjoyment, and the world is organized for their erotic pleasure. Biology is a very important element of this type of approach to women. The submodel LOVE AND SEX seems to be the most extensive and the most productive one, with as many as 122 excerpts identified.

Thirdly, the aforementioned features that have been traced, of course, do not exhaust all of the attributes that can be assigned to women, which is why particular subsets are open. However, it is believed here that this account covers the major criteria for female differentiation, at least within Western civilisation, and it seems that they can be treated as a set of characteristics, consisting of a stereotypical image of a woman in Western culture. What is also worth emphasising is that the magazines seem to justify men creating a particular overgeneralized portrayal of women, which ultimately leads to the formulation of certain sexist stereotypes of what a woman is expected to be. It furthermore contributes to the linguistic oppression of the feminine gender but also has baleful effects on the struggle for gender equality. It is believed that language plays an extremely significant role in stereotypes. Its main side-effect, transmitted and maintained within a given society, is an oversimplified image of females.

As a conclusion it can be stated that the American pornographic press promotes a number of cognitive submodels mapped onto complex clusters that seem to degrade female roles. There is a general tendency towards negative representation of women in the form of prototypes that embody submodels such as LOVE AND SEX, PHYSICAL TRAITS and BODY. Admittedly, the whole rich content of the stereotypical ICM of a woman is modelled from the perspective of one magazine in which the lexeme appears. It largely depends on the adopted model of reality and knowledge about the world, but also on the ideological orientation of the authors and their intention. Individual domains and models are the effect of these subjective factors. The stereotype of the woman reconstructed in this article constitutes a linguistic and cultural view of reality. The findings are predominantly hypothetical, and the main aim of this article was to shed some light on the interaction between social and cognitive factors related to the perception of women in pornographic magazines (here "Penthouse" $)^{25}$. The analysis of linguistic data allows us to develop a practical model of

25 The conclusions stemming from the above analysis should be viewed as tentative and certainly not final and binding. The collected material is only a fraction of what can be found in many other magazines, both for women and for men. 
WOMAN that is useful for the formulation of some plausible interpretations of linguistic data that appear in this sector of the magazine industry.

\section{REFERENCES}

Cheney, V.T. (2004). The Sex Offenses and Their Treatments: The Problem - The SolutionThe Commentary. Bloomington, Indiana: AuthorHouse.

Evans, V., Green, M. (2006). Cognitive Linguistics: An Introduction. Edinburgh: Edinburgh University Press.

Gibbs, R.W. Jr. (1999). Taking Metaphor out of our Heads and Putting it into the Cultural World [in:] Gibbs, R.W. Jr., Steen, G.J., eds., Metaphor in Cognitive Linguistics. Amsterdam: John Benjamins.

Gunter, B. (2002). Media Sex: What are the Issues? London and New York: Routledge.

Kappeler, S. (1994). From Sexual Politics to Body Politics [in:] Cameron, D., Scanlon, J., eds., The Trouble \& Strife Reader. London, New York: Bloomsbury Academic.

Kövecses, Z. (2005). Metaphor in Culture. Cambridge: Cambridge University Press.

Kövecses, Z., Radden, G. (1998). Metonymy, Developing a Cognitive Linguistic Approach. "Cognitive Linguistic", 9.1.

Lakoff, G. (1987). Women, Fire, and Dangerous Things: What Categories Reveal About the Mind. Chicago: Chicago University Press.

Langacker, R.W. (1987). Foundations of Cognitive Grammar. Theoretical Prerequisites. Stanford: Stanford University Press.

- (2008). Cognitive Grammar: A Basic Introduction. Oxford: Oxford University Press.

Rosch, E. (1973). Natural Categories. "Cognitive Psychology" 4.

- (1977). Human Categorization [in:] Warren, N., ed., Studies in Cross-cultural Psychology. London: Academic Press, Vol. 1.

- (1978). Principles of Categorization [in:] Rosch, E., Lloyd B.B., eds., Cognition and Categorization. Hillside: Lawrence Erlbaum.

Spychała-Reiss, M. (2009). Językowy Obraz Kobiety w Prasie dla Pań (na przyktadzie 'Zwierciadta', 'Przyjaciótki' $i$ 'Cosmopolitan'. "Poznańskie Studia Polonistyczne. Seria Językoznawcza", Vol. 15.

Środa, M. (2009). Kobiety i władza. Warszawa: Wydawnictwo W.A.B.

Taylor, J. (1995). Linguistic Categorisation. Prototypes in Linguistic Theory. Cambridge: Cambridge University Press.

Wykes, M., Gunter, B. (2005). The Media and Body Image: If Looks Could Kill. London: SAGE.

DOI: $10.7862 /$ rz.2019.hss.27

The text was submitted to the editorial office: July 2019.

The text was accepted for publication: September 2019. 